\title{
Harmonics resonance elimination technique using active static compensation circuit
}

Rakan Khalil Antar, Mohammed Y. Suliman, Asef A. Saleh

Technical Engineering College, Northern Technical University, Mosul, Iraq

\begin{tabular}{|c|c|}
\hline Article Info & ABSTRACT \\
\hline Article history: & The existence of nonlinear loads produces high distortion and low power \\
\hline Received Jun 19, 2020 & $\begin{array}{l}\text { factor in the power system that leads to get poor power quality. Resonance } \\
\text { problem is occurred due to the power system inductances and the }\end{array}$ \\
\hline Revised Feb 20, 2021 & compensation capacitors which increases the harmonic distortion. Therefore, \\
\hline Accepted Jul 27, 2021 & it is necessary to prevent the action of resonance even if conventional or \\
\hline Keywords: & $\begin{array}{l}\text { active static compensation circuit is proposed and designed to have the } \\
\text { features of improving power factor, reducing THD, and eliminating the }\end{array}$ \\
\hline $\begin{array}{l}\text { Active static compensation } \\
\text { circuit }\end{array}$ & $\begin{array}{l}\text { harmonics resonance effect at the same time with different linear and } \\
\text { nonlinear load conditions. These features have been performed based on a } \\
\text { modified pulse width modulation technique to drive and control the proposed }\end{array}$ \\
\hline Harmonics resonance & circuit. The originality designed point of this technique is to have ability to \\
\hline Linear and nonlinear loads & operate the active static compensation circuit as harmonics injector, power \\
\hline Modified PWM technique & factor corrector and resonance eliminator at the same time. Simulation model \\
\hline Power factor correction & $\begin{array}{l}\text { results illustrate that the proposed circuit is effective for both steady-state and } \\
\text { transient operations conditions. The THD of the supply voltage and current at } \\
\text { firing angle }\left(\alpha=30^{\circ}\right) \text { is reduced by } 99 \% \text { and } 98.8 \% \text { respectively. While the } \\
\text { power factor is improved to stay around unity. }\end{array}$ \\
\hline
\end{tabular}

This is an open access article under the CC BY-SA license.

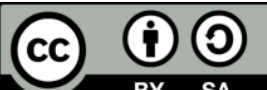

Corresponding Author:

Rakan Khalil Antar

Technical Engineering College/Mosul

Northern Technical University, Iraq

Email: rakan.antar@ntu.edu.iq

\section{INTRODUCTION}

Most industrial power system loads are nonlinear, which cause distortions in AC voltage and current waveforms, and in magnetic fields [1]. The generated harmonics due to nonlinear load flows through the power system that needed to eliminate or reduce as minimum as possible [2]. Passive and active power filters are used to solve this effect [3], [4]. Capacitor banks can be used to correct poor input power factor. As a results, power system inductances and capacitances may produce resonance with each other at certain frequencies, which is called resonance frequency [5]. Also, power cables add shunt capacitance to the grid which may increase the happening resonance probability [6]. In addition, series compensation may produce oscillation in the generator shaft due to subsynchronous resonance [7]. As a result, a standard harmonics can be greater than before if resonance happens at or close to critical frequencies which increase the voltage distortion to levels above of the acceptable limits. This effect can be avoided depending on the application of power factor correction capacitors or power harmonic filters [8]. In many algorithm methods, the system has been considered in time-domain methods like PQ and synchronous-reference theory [9], or in frequencydomain like fast Fourier transform [10]-[12].

Harmonic problems and poor input power factor encourage reearschers to get solutions with developing of power electronics devices and applications. The harmonic distortion in AC side currents of the 
thyristor or diode converters leads to use passive filter at one or more specific frequencies. Also active power filters are used to improve power quality of the AC/DC converters. The highly distorted waveforms due to resonance may perhaps produce mal-operation of the protection devices, electromagnetic communication interference, increase tempreture of transformers, vibration, and overloading of power factor correction capacitors [13]-[17]. Due to rise demand of electrical trains and increase power dememands, harmonics resonance pollution has become a main interest in both power system quality and renewable enegy sources.

In 2015 [18], a $7^{\text {th }}$ tuned passive power filter coupled in series with active filter to minimize the distortion problem due to harmonic resonance effect in industrial nonlinear and linear loads. In the same year [19], to prevent occurring resonances in high speed railways in China, a harmonics resonance elimination pulse width modulation (PWM) technique was designed and built. The results were at acceptable levels. In 2017 [20], parallel and series filters were used to reduce harmonics in a textile industry in Nigeria. The harmincs are mitigated to IEEE standards, while power factor was improved using capacitor banks. Also, a single-phase uncontrolled rectifier based on a boost converter with power decoupling was developed as a circuit to correct power factor. The system improved input power factor around 0.99 and reduced total harmonics distortion (THD) less than 12\% [21]. In 2018 [22], a LLC circuit is tuned at specific resonant frequency to reduce the power switching losses of LLC resonant converter to improve the battery charging efficiency in the electric vehicle. The system is tested experimentally and the total efficiency is raised to 93.7\%. Recently in 2019 [23], the influence of harmonics on the grid when connected with PWM converters and LCL filters was investigated. For suppressing harmonic current components, a modified converter current feedback controller has been suggested. In 2020 [24], active filter was considered and used to minimize THD and improve power factor of the BLDC drive system. The THD is reduced by $95.2 \%$ and $89.5 \%$ with sinusoidal and non-sinusoidal source voltage conditions. While power factor improved and became around unity.

The previous works concentrated on eliminating harmonics resonance problem or minimizing harmonics and/or improving power factor to recover the power system quality. According to the previous works, the contribution of this study is to design and built an active static compensation circuit (ASCC) to recover the power system quality. The ASCC is designed to damp resonance, minimize THD, and increase input power factor at the same time depending on advance control technique suggested by [25] after a modification to suit the aim of the present paper. Therefore, the ASCC shown in Figure 1 is regarded as resonance harmonics eliminator and power factor corrector for wide load type conditions.

\section{RESONANCE EFFECTS}

Oscillations in power system due to resonance event may cause several problems. Harmonic resonance causes unstable power network system and collapse or damage may occur to power electrical equipments and plants. The resonance problems can be excited due to faults, interaction of reactor or capacitor banks existence, and the operation nature of non-linear loads such as power electronic applications [8]. For typical example, passive filters use to eliminate significant harmonics components, but the filter elements cause resonances with the supply inductances at other frequencies. As a result, to overcome resonance, passive power filter needs to be modified and retuned depending on the system impedances and therefore passive power filter becomes expensive.

The electrical power system reactance depends on natural frequency. At resonance frequency, the inductance and capacitance elements of the power system bring to resonate with each other. The resonance frequency is identified by the integration of the inductors and capacitors. The resonant frequency equation is given as:

$$
f_{o}=\frac{1}{2 \pi \sqrt{L C}}
$$

Where $\mathrm{C}$ and $\mathrm{L}$ are the capacitance and inductance of the system. In this paper, ASCC is used to eliminate the harmonics resonance problem caused by the system impedances and correct poor power factor.

\section{ACTIVE STATIC COMPENSATION CIRCUIT}

Power quality improvement is one of the main research care. The ASCC is used to recover the power system quality of the suggested system. The ASCC shown in Figure 1 is a single-phase H-bridge inverter connected in parallel through coupling inductor at the AC side of the power system. The ASCC is designed and controlled depending on a modified PWM (MPWM) algorithm. This type of a new active 
power filter designs to eliminate resonance problems caused in the AC power system, minimize THD, and accurate power factor as the same time depending on the MPWM algorithm [25].

In the MPWM algorithm, the reference compensated current $\left(i_{c}\right)$ is calculated as the difference between the load current signal $\left(I_{L}\right)$ and the desired reference AC current signal $\left(i_{d-r e f}\right)$. The $i_{d-r e f}$ is produced as the product of the both unity sinusoidal waveform of the main voltages $(\sin (w t))$ and the fundamental component of the load current $\left(I_{L I}\right)$ [25].

$$
I_{d-r e f}=I_{L 1} * \sin (\mathrm{wt})
$$

The $\left(i_{c}\right)$ signal equation for the ASCC is:

$$
i_{c}=I_{L}-i_{d-r e f}
$$

The $\left(i_{c}\right)$ is contrasted with the ASCC current $\left(i_{A S C C}\right)$ and the product signal is used as a reference signal for the PWM model, which is contrasted with a carrier signal to get PWM pulses of the insulated gate bipolar transistors of the ASCC as illustrated in Figure 2.

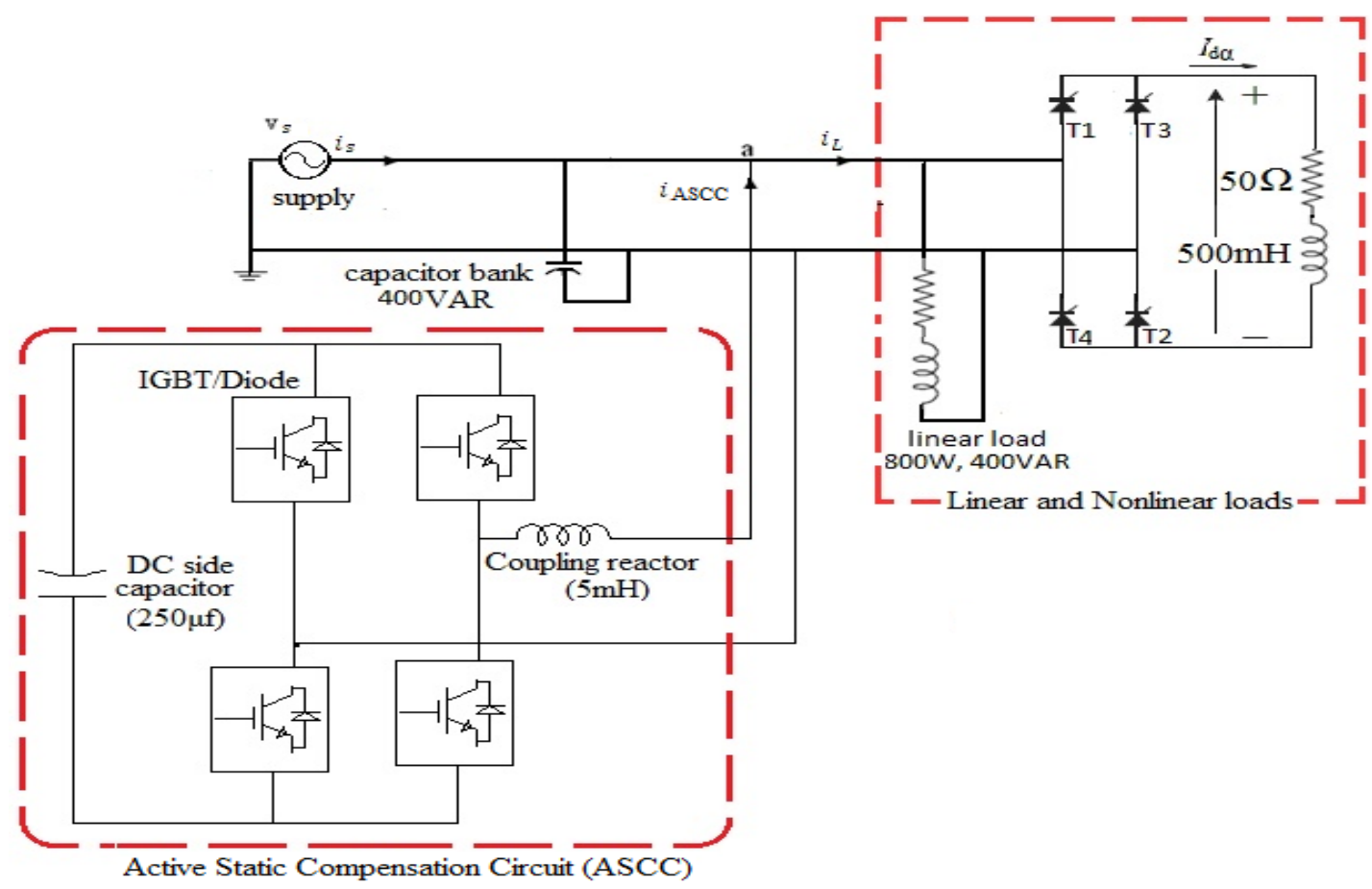

Figure 1. Circuit diagram of the nonlinear and linear loads with the suggested ASCC

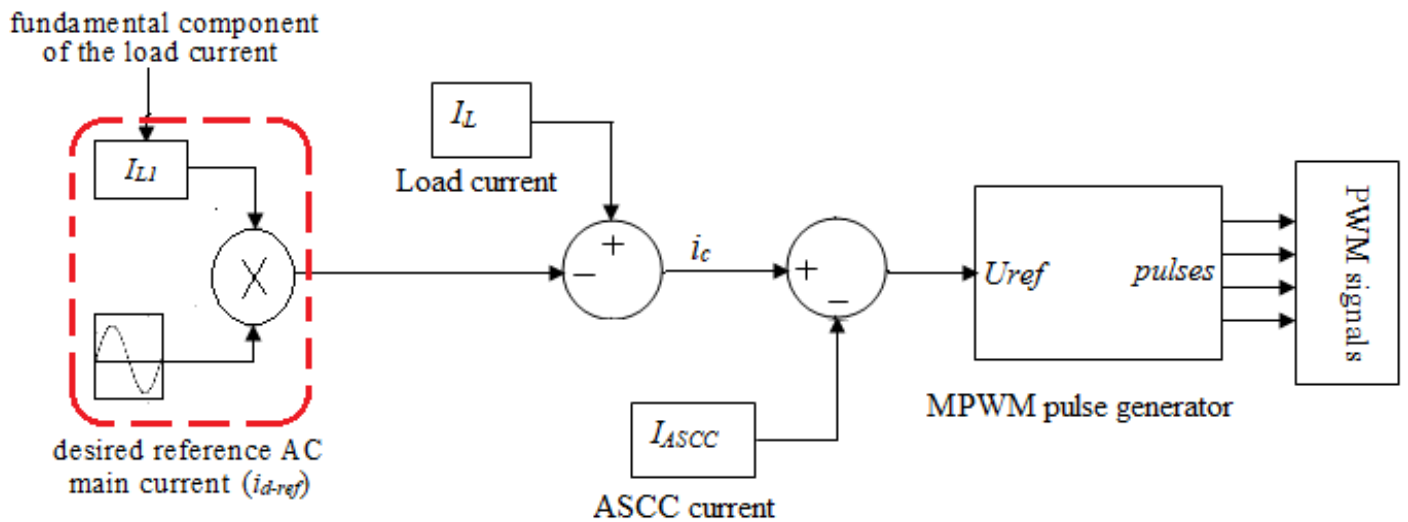

Figure 2. Control circuit of the suggested ASCC 


\section{POWER COMPONENTS DEFINITIONS}

In the power system with nonsinusoidal voltage and current, voltage and current equations are presented as [26]:

$$
\left.\begin{array}{l}
i_{1}=\sqrt{2} I_{1} \sin \left(w t-\theta_{1}\right), i_{H}=\sqrt{2} \sum_{h=2}^{\infty} I_{h} \sin \left(h . w t-\theta_{h}\right) \\
v_{1}=\sqrt{2} V_{1} \sin \left(w t-\varphi_{1}\right), v_{H}=\sqrt{2} \sum_{h=2}^{\infty} V_{h} \sin \left(h . w t-\varphi_{h}\right)
\end{array}\right\}
$$

Where $\theta_{\mathrm{h}}, \theta_{1}, \mathrm{i}_{\mathrm{h}}$, and $\mathrm{i}_{1}$ represent the phase angles relating to the supply voltage $\mathrm{v}_{\mathrm{h}}$ and $\mathrm{v}_{1}$, the harmonics and fundamental components of supply current, respectively. The effective RMS of the nonsinusoidal current and voltage is defined as:

$$
\begin{aligned}
& V_{T}=\sqrt{{V_{1}{ }^{2}+{V_{H}}^{2}+V_{d c}{ }^{2}}_{4}} \\
& \left.I_{T}=\sqrt{{I_{1}}^{2}+{I_{H}}^{2}+I_{d c}{ }^{2}}\right\}
\end{aligned}
$$

Where $V_{\mathrm{dc}}$ and $\mathrm{I}_{\mathrm{dc}}$ are dc voltage and current components. The total harmonic distortion are defined as:

$$
T H D=\frac{\sqrt{U_{T}^{2}-U_{1}^{2}}}{U_{1}}
$$

The total apparent power $\left(\mathrm{S}_{\mathrm{T}}\right)$, reactive power $\left(\mathrm{Q}_{\mathrm{T}}\right)$, active power $\left(\mathrm{P}_{\mathrm{T}}\right)$, and distortion power for nonsinusoidal waveform are defined as:

$$
\left.\begin{array}{l}
P_{T}=V_{1} I_{1} \cos \left(\psi_{1}\right)+\sum_{h=2}^{\infty} V_{h} I_{h} \cos \left(\psi_{h}\right)+V_{\mathrm{dc}} I_{\mathrm{dc}} \\
Q_{T}=V_{1} I_{1} \sin \left(\psi_{1}\right)+\sum_{h=2}^{\infty} V_{h} I_{h} \sin \left(\psi_{h}\right) \\
S_{T}=V_{1} I_{1}+V_{H} I_{H} \\
D_{T}=\sqrt{\sum_{m \neq n=1}^{\infty} V_{m}{ }^{2} I_{n}{ }^{2}} \\
D_{T}=\sqrt{S_{T}{ }^{2}-P_{T}{ }^{2}-Q_{T}{ }^{2}}
\end{array}\right\}
$$

where $\psi_{h}=\varphi_{h}-\theta_{h}$ and $\mathrm{n}, \mathrm{m}$ represent harmonics order for voltage and current respectively. The effective input power factor terms are defined and represented as:

$$
p f_{E}=\frac{\text { Total Real Power }}{\text { Total Apparent Power }}=\frac{P_{T}}{S_{T}}
$$

\section{SIMULATION RESULTS}

The power circuit during harmonic resonance problem is modelled, validated and tested. A singlephase linear load (different RL loads) with ac/dc controlled converter circuit as a nonlinear load is chosen as shown in Figure 1. Capacitor banks are added to correct power factor which produce harmonics resonance at certain load condition. The ASCC is simulated dynamically at different values of firing angles. The system is modelled as a $220 \mathrm{~V}, 50 \mathrm{~Hz}$ with source impedance $(\mathrm{Rs}=3 \mathrm{~m} \Omega$ and $\mathrm{Ls}=5 \mathrm{mH})$ using MATLAB/SIMULINK. The values of $\mathrm{L}_{c}$ and $\mathrm{C}_{\mathrm{dc}}$ are selected equal to $5 \mathrm{mH}$ and $250 \mu \mathrm{F}$, respectively. The supply AC voltage (vs) and current (is) and its FFT spectrum analyzer at thyristor firing angle $\left(\alpha=30^{\circ}\right)$ without and with the ASCC are presented in Figure 3 and Figure 4, respectively. The waveforms of the supply AC voltage and current are inphase once linking the ASCC. Also the harmonics resonance is completely removed and this is due to the nature behaviour of the suggested ASCC. The normalized FFT analysis shown in Figure 3 is plotted with respect to fundamental value and illustrated that the supply voltage and current before connecting ASCC have a significant amount of $9^{\text {th }}$ harmonic order, which is unacceptable and affected badly on the power network system. After connecting the ASCC, the $9^{\text {th }}$ harmonic order as explained in Figure 4 is reduced by $99.87 \%$. The value of effective input power factor is increased about $50.56 \%$ (0.9999 Lagging) and the THD of the AC supply voltage and current decreased by $99.14 \%$ and $98.78 \%$ respectively.

The curve relations of the effective input power factor and THD of the AC voltage and current with and without the suggested ASCC at a wide range of firing angles of the ac/dc converter circuit are illustrated in Figure 5 and Figure 6. These results confirm that the effective input power factor stay around unity and THD results are improved after connecting the ASCC. Also, the success of the ASCC is demonstrated by the AC distortion power waveform shown in Figure 7, which proves the THD results. As well as, the reactive 
power supplied by the AC source, Figure 8, is almost disappeared which verify effectiveness of the suggested ASCC in correcting power factor. As a result, the amount of real power supplied through the AC power system is raised as illustrated in Figure 9. The steady state and dynamic operating conditions of the ASCC to remove harmonics resonance and improve power factor during fault condition at $\mathrm{AC}$ voltage side is explained in Figure 10. It can be seen that the ASCC restore itself by improving the power system quality.

At firing angle around $90^{\circ}$, the single phase bridge controlled rectifier becomes out of work. Linear (RL) load with capacitor bank produce in-phase supply voltage and current with THD around zero and no resonance problem as illustrated in figures. This means that chosen linear and nonlinear loads together produce resonance with very bad power quality and the ASCC solve this issue.

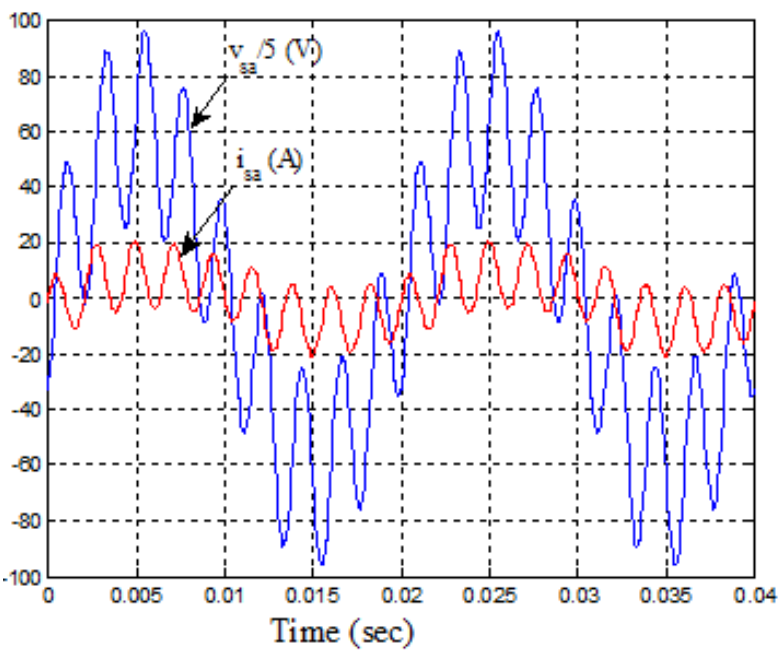

(a)

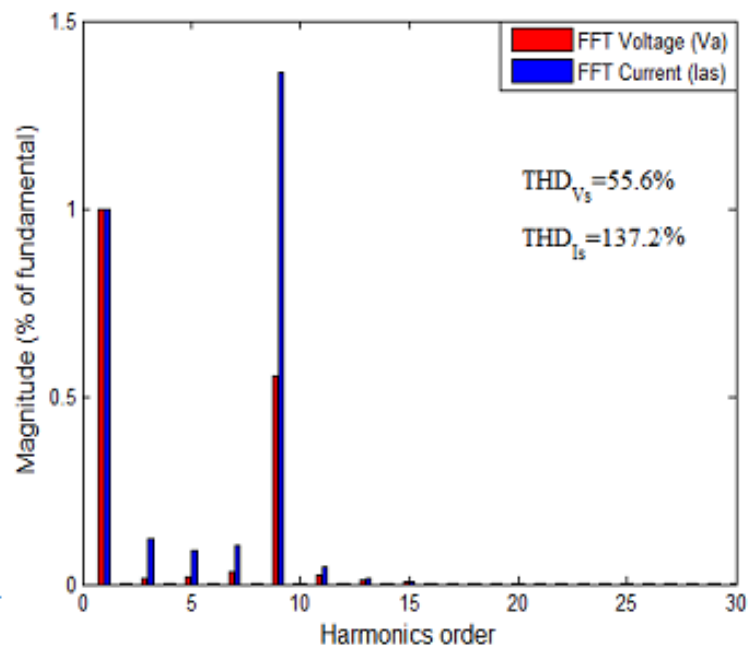

(b)

Figure 3. Simulation results of the power circuit without ASCC at firing angle $\left(\alpha=30^{\circ}\right)$; (a) AC supply voltage and current, (b) FFT analysis of supply voltage (Vs) and current (Is)

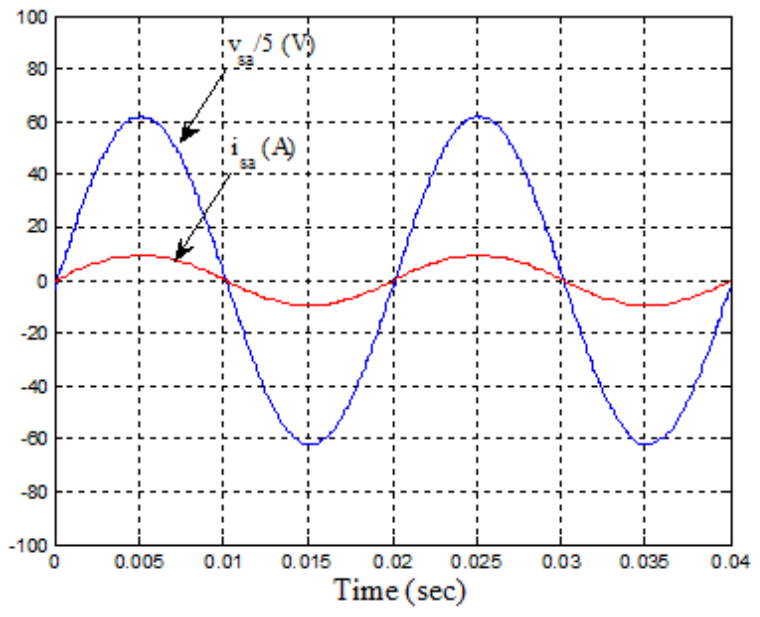

(a)

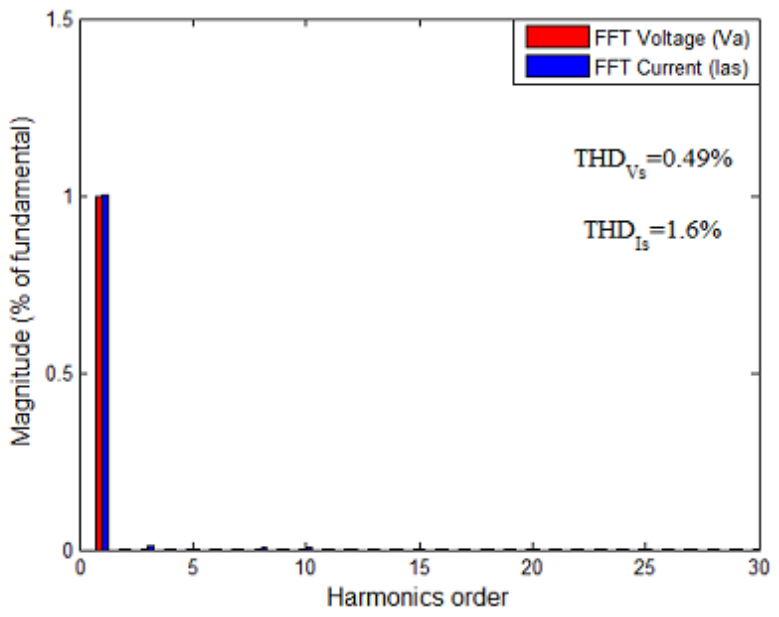

(b)

Figure 4. Simulation results of the power circuit with ASCC at firing angle $\left(\alpha=30^{\circ}\right)$; (a) AC supply voltage and current, (b) FFT analysis of supply voltage (Vs) and current (Is) 


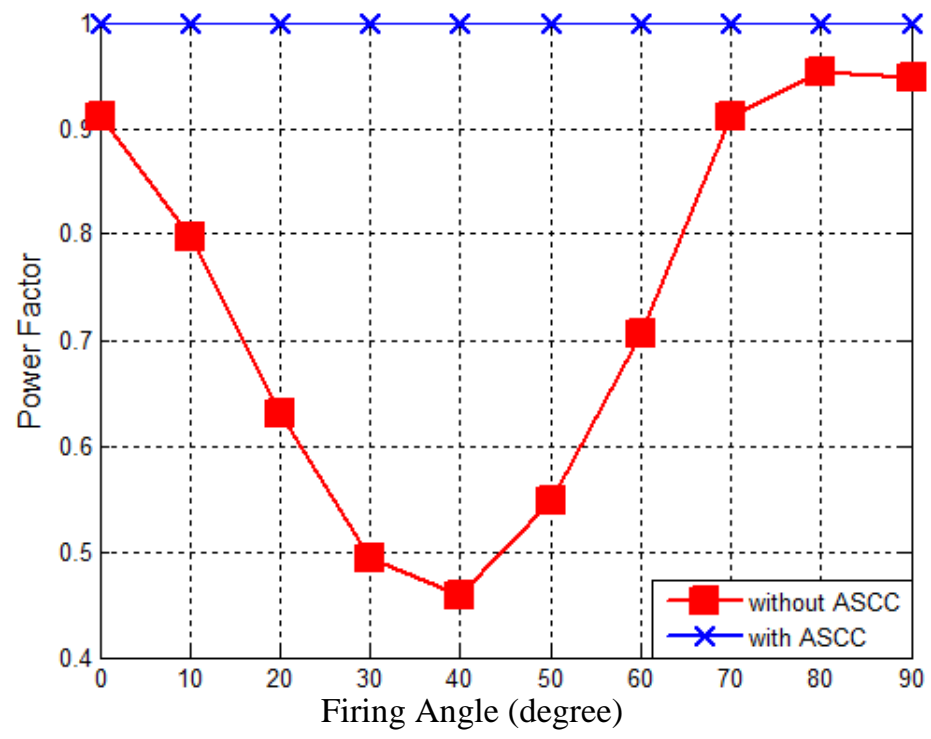

Figure 5. Effective input power factor with and without the suggested ASCC

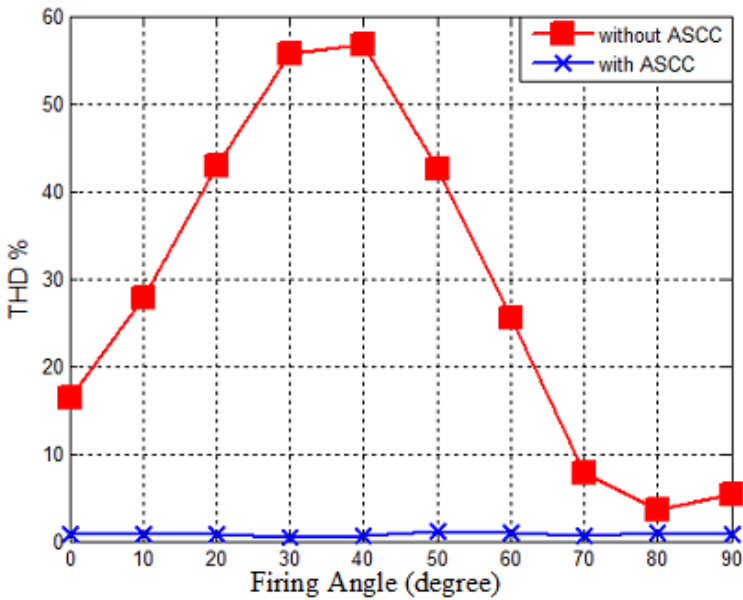

(a)

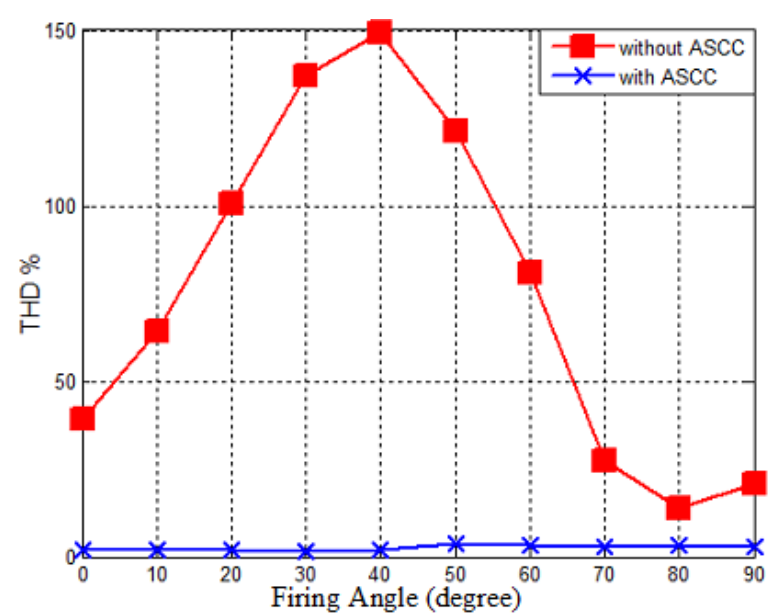

(b)

Figure 6. THD of the; (a) AC supply voltage, (b) current with and without the suggested ASCC

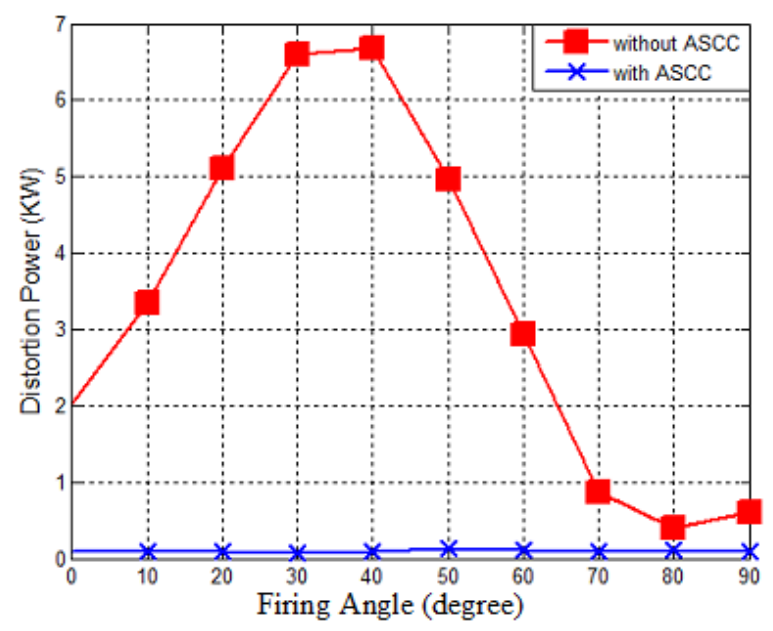

Figure 7. Distortion power with and without ASCC

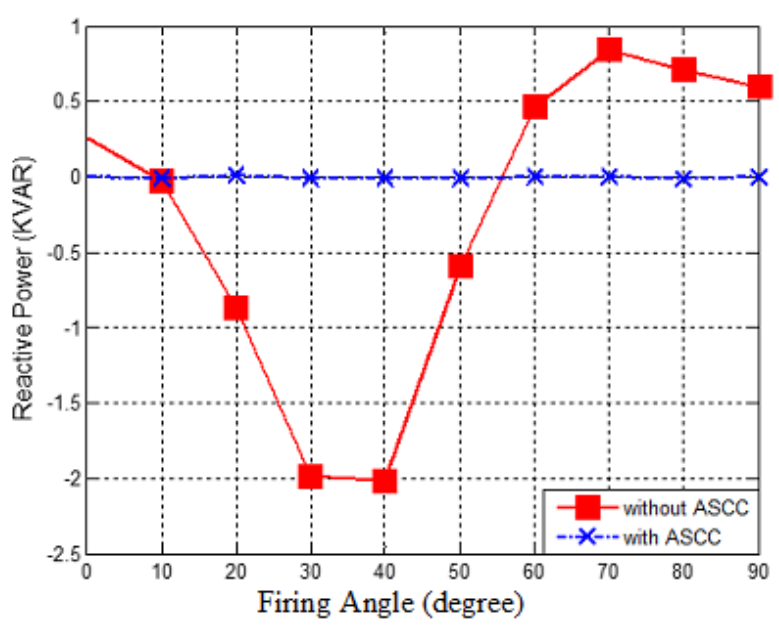

Figure 8. Reactive power with and without ASCC 


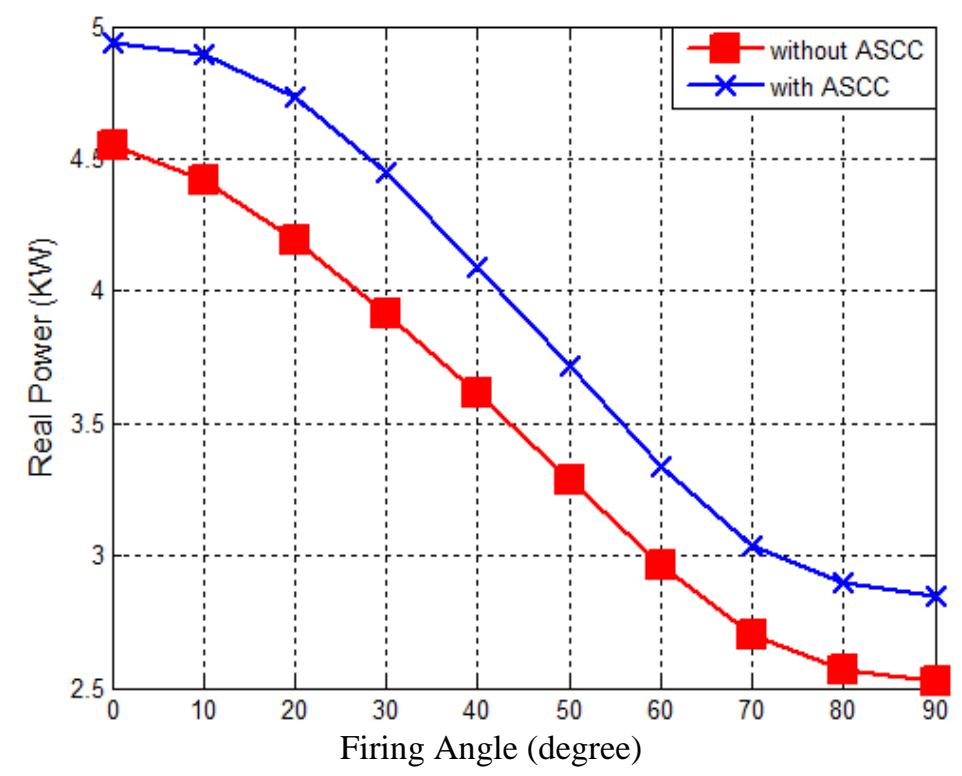

Figure 9. Real power results with and without the suggested ASCC
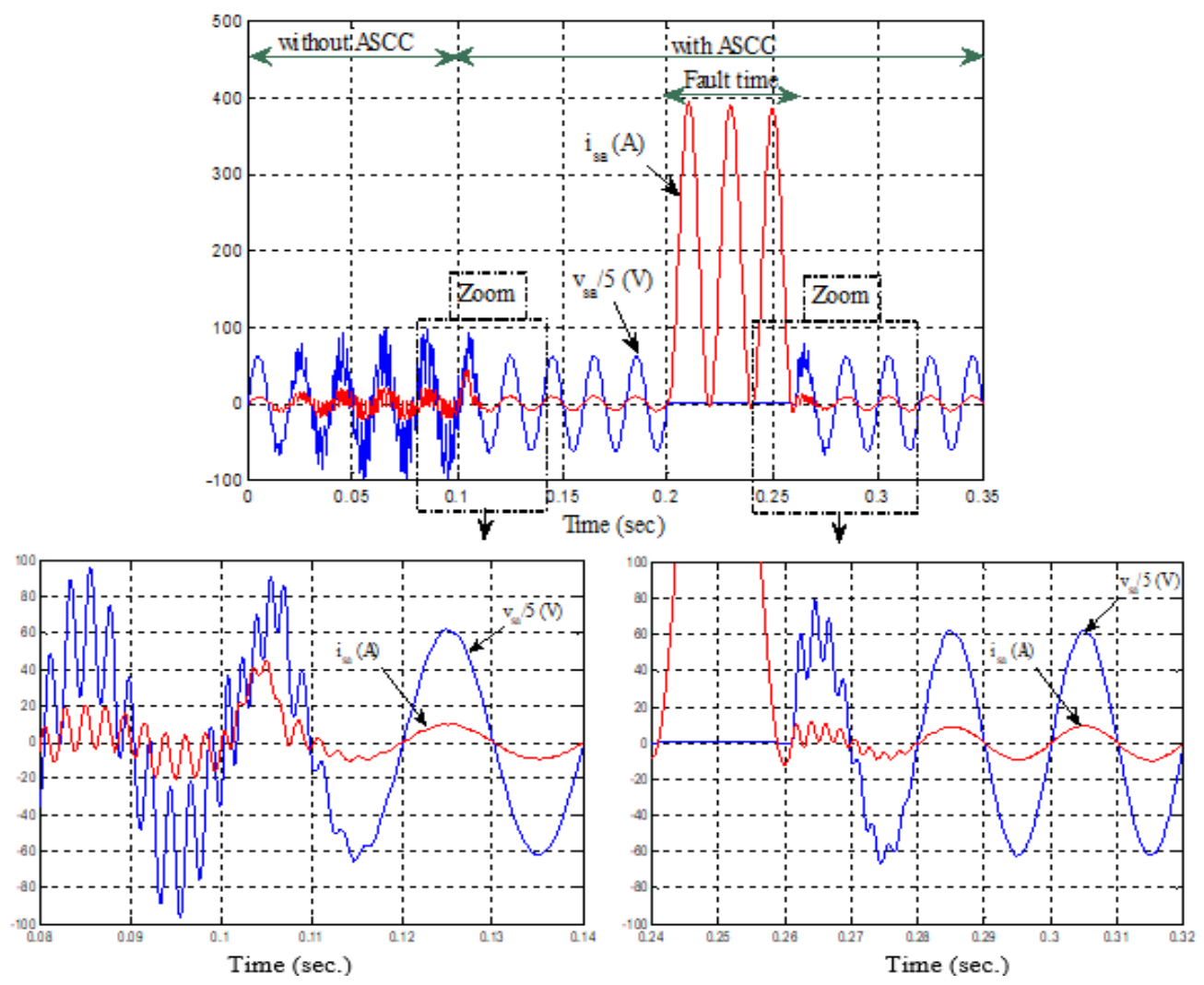

Figure 10. Steady-state and dynamic results during fault effect without and with the ASCC

\section{CONCLUSIONS}

A new technique for damping harmonic resonances in power supply system has been proposed. The aim of this article is to exist a different active power filter circuit, which is ASCC. The ASCC is proper for linear and nonlinear loads. The system at the time of resonance phenomenon problem without and with the ASCC have been modeled. The MPWM algorithm is used to drive the ASCC to remove resonance and keep THD and input power factor at different values of firing angles as best as possible. Therefore, it is acted as a resonance eliminator, harmonics reducer and power factor corrector at the same time. The simulation results

Harmonics resonance elimination technique using active static compensation circuit (Rakan Khalil Antar) 
verify the efficiency of the suggested ASCC in steady state and dynamic operating conditions at normal and abnormal conditions. The THD of the AC voltage and current has been minimized significantly at different firing angles. Also, the resonance problem completely has been removed. While the input power factor is enhanced to stay around unity. The benefits of the proposed method being more flexibility to the power quality improvement when comparing with other approaches in the literature. As future work, the proposed model will be expanded for three-phase system with different linear and nonlinear loads rather than single-phase system.

\section{REFERENCES}

[1] A. Y. Al-Rawashdeh, A. Dalabeeh, A. Al-Zeyod, A. Samarah, G. Qaryouti, and O. Albarbarawi, "The tooth factor effect on the harmonics of large electrical machines," Bulletin of Electrical Engineering and Informatics (BEEI), vol. 9, no. 4, pp. 1677 1684, 2020, doi: 10.11591/eei.v9i4.1565.

[2] T. Tran, D. Raisz, and A. Monti, "Harmonic and unbalanced voltage compensation with VOC-based three-phase four-leg inverters in islanded microgrids," IET Power Electronics, vol. 13, no. 11, pp. 2281-2292, 2020, doi: 10.1049/iet-pel.2020.0174.

[3] M. A. Hutabarat, S. Hasan, A. H. Rambe, and S. Suherman, "Design and simulation hybrid filter for 17 level multilevel inverter," Bulletin of Electrical Engineering and Informatics (BEEI), vol. 9, no. 3, 886-897, 2020, doi: 10.11591/eei.v9i3.890.

[4] S. H. Mohamad, et al., "Adaptive notch filter under indirect and direct current controls for active power filter," Bulletin of Electrical Engineering and Informatics (BEEI), vol. 9, no. 5, pp. 1794 1802, 2020, doi: 10.11591/eei.v9i5.2165.

[5] N. Eghtedarpour, M. A. Karimi, and M. Tavakoli, "Harmonic Resonance in Power Systems-A Documented Case," 16th International Conference on Harmonics and Quality of Power (ICHQP)-Bucharest, Romania, pp. 857-861, 2014, doi: 10.1109/ichqp.2014.6842806.

[6] O. Lennerhag and M. H. J. Bollen, "Power system impacts of decreasing resonance frequencies," 2018 18th International Conference on Harmonics and Quality of Power (ICHQP), 2018, pp. 1-6, doi: 10.1109/ICHQP.2018.8378880.

[7] D. D. Tung, L. V. Dai, and L. C. Quyen, "Subsynchronous Resonance and FACTS-Novel Control Strategy for Its Mitigation”, Journal of Engineering, vol. 2019, pp. 1-14, 2019, doi: 10.1155/2019/2163908.

[8] M. Z. El-Sadek, M. A. A. Wahab, M. Hamada, and M. R. Ghallab, "Damping techniques of harmonic resonances", Journal of Engineering, Science, Assiut University, vol. 35, no.5, pp. 1271-1281, 2007, doi: 10.21608/JESAUN.2007.114555.

[9] H. Akagi, E. H. Watanabe, and M. Aredes, "Instantaneous Power Theory and Applications to Power Conditioning," Hoboken, New Jersey: IEEE Press/Wiley, second edition 2017.

[10] H. Chen, H. Liu, Y. Xing and H. Hu, "Enhanced DFT-Based Controller for Selective Harmonic Compensation in Active Power Filters," in IEEE Transactions on Power Electronics, vol. 34, no. 8, pp. 8017-8030, Aug. 2019, doi: 10.1109/TPEL.2018.2877848.

[11] A. Risdiyant, B. Susanto, N. A. Rachman, A. Muqorobin, T. D. Atmaja, and H. P. Santosa, "Design of constant output voltage DC-AC inverter for batteryless solar PV system," Bulletin of Electrical Engineering and Informatics (BEEI), vol.9, no.4, pp. 1326 1334, 2020, doi: 10.11591/eei.v7i3.945.

[12] A. Rahnamaei and M. Salimi, "A novel grid connected photovoltaic system," Bulletin of Electrical Engineering and Informatics (BEEI), vol. 5, no. 2, pp. 133-143, 2016, doi: 10.11591/eei.v5i2.523.

[13] H. Hu, Y. Shao, L. Tang, J. Ma, Z. He, and S. Gao, "Overview of Harmonic and Resonance in Railway Electrification Systems," in IEEE Transactions on Industry Applications, vol. 54, no. 5, pp. 5227-5245, Sept.-Oct. 2018, doi: 10.1109/TIA.2018.2813967.

[14] D. Kumar, and F. Zare, "Harmonic Analysis of Grid Connected Power Electronic Systems in Low Voltage Distribution Networks," in IEEE Journal of Emerging and Selected Topics in Power Electronics, vol. 4, no. 1, pp. 70-79, March 2016, doi: 10.1109/JESTPE.2015.2454537.

[15] M. Y. Suliman, and M. T. Al-Khayyat, "Power flow control in parallel transmission lines based on UPFC", Bulletin of Electrical Engineering and Informatics (BEEI), vol. 9, no. 5, pp. 17551765, 2020, doi: 10.11591/eei.v9i5.2290.

[16] S. Samal, and P. K. Hota, "Wind Energy Fed UPQC System for Power Quality Improvement," Bulletin of Electrical Engineering and Informatics (BEEI), vol. 7, no. 3, pp. 495 504, 2018, doi: 10.11591/eei.v7i3.945.

[17] N. Elhaj, M. B. Sedra, and H. Djeghloud, "DFPI-based control of the DC-bus voltage and the AC-side current of a shunt active power filter," Bulletin of Electrical Engineering and Informatics (BEEI), vol. 5, no. 4, pp. 430-441, 2016, doi: 10.11591/eei.v5i4.572.

[18] T. Lee, Y. Wang, J. Li and J. M. Guerrero, "Hybrid Active Filter With Variable Conductance for Harmonic Resonance Suppression in Industrial Power Systems," in IEEE Transactions on Industrial Electronics, vol. 62, no. 2, pp. 746-756, Feb. 2015, doi: 10.1109/TIE.2014.2347008.

[19] H. Cui, W. Song, H. Fang, X. Ge, and X. Feng, "Resonant harmonic elimination pulse width modulation-based high-frequency resonance suppression of high-speed railways," IET Journal of Power Electronics, vol. 8, issue 5, pp. 735-742, 2015.

[20] I. A. Adejumobi1, O. I. Adebisi, and J. E. Amatu, "Harmonics Mitigation on Industrial Loads using Series and Parallel Resonant Filters," Nigerian Journal of Technology, vol. 36, No. 2, pp. 611-620, 2017, doi: 10.4314/njt.v36i2.37. 
[21] W. Chen, T. Wu, Y. Hsieh, C. Moo and P. Wen, "Power-Factor-Correction with Power Decoupling for AC-to-DC Converter," 2018 International Power Electronics Conference (IPEC-Niigata 2018 -ECCE Asia), 2018, pp. 3544 3548, doi: 10.23919/IPEC.2018.8507366.

[22] Z. Zhao, Q. Xu, Y. Dai, and A. Luo, "Minimum resonant capacitor design of highpower LLC resonant converter for comprehensive efficiency improvement in battery charging application," IET Power Electronics, vol. 11, no. 11, pp. 1866-1874, 2018, doi: 10.1049/iet-pel.2017.0649.

[23] R. Zhao, Q. Li, H. Xu, Y. Wang and J. M. Guerrero, "Harmonic Current Suppression Strategy for Grid-Connected PWM Converters With LCL Filters," in IEEE Access, vol. 7, pp. 16264-16273, 2019, doi: 10.1109/ACCESS.2019.2893226.

[24] S. Kumaresan and H. Habeebullah Sait, "Design and control of shunt active power filter for power quality improvement of utility powered brushless DC motor drives," Automatika, Journal for Control, Measurement, Electronics, Computing and Communications, vol. 61, no. 3, pp. 507-521, 2020, doi: 10.1080/00051144.2020.1789402.

[25] R. K. Antar, B. M. Saied and R. A. Khalil, "Using seven-level cascade H-bridge inverter with HVDC system to improve power quality," 2012 First National Conference for Engineering Sciences (FNCES 2012), 2012, pp. 1-7, doi: 10.1109/NCES.2012.6740457.

[26] B. M. Saied and R. K. Antar, "The investigation of power distortion in a three-phase modified controlled converter circuit," 2010 7th International Multi-Conference on Systems, Signals and Devices, 2010, pp. 1-6, doi: 10.1109/SSD.2010.5585595.

\section{BIOGRAPHIES OF AUTHORS}

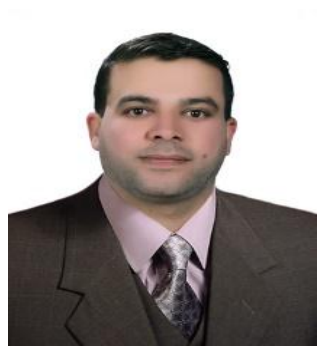

Assist. Prof. Dr. Rakan Khalil Antar got his B.Sc., M.Sc. and Ph. D. degrees from University of Mosul, Iraq in 2002, 2005 and 2013 respectively. Now, he is a lecturer in Technical Engineering College/Mosul, Northern Technical University, Iraq. He is concerned in power electronics, power quality, power converters and drives, and renewable energies.

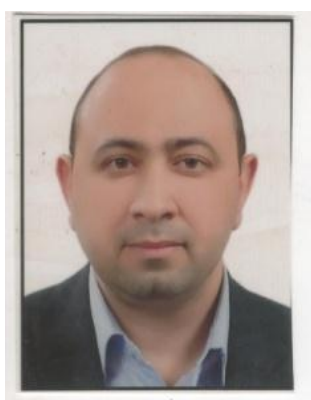

Assist. Prof Dr. Mohammed Y. Suliman received his BSc, M.Sc. and Ph. D. degrees from University of Mosul, Iraq in 1995, 1998 and 2014 respectively. Currently, he is a head of Elect. Power Eng. dept. at Technical Engineering College, Northern Technical University. His research interests, include power system assessment, Power Electronics, FACTS, Renewable energy.

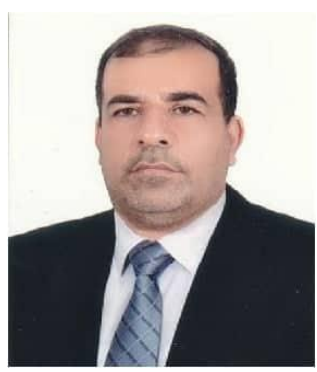

Dr. Asef A. Saleh received his BSc, M.Sc. and Ph. D. degrees from University of Mosul, Iraq in 1990, 2006 and 2018 respectively. Currently, he is a lecturer in Elect. Power Eng. dept. at Technical Engineering College, Northern Technical University. His research interests include power electronics, power quality, and power converters and drives. 